\title{
EXPERIMENTAL MIXED-MEDIA PAINTING WITH PERSONAL COMPUTER MOTHERBOARDS
}

\section{OKON AYI}

(Received 4 April 2018; Revision Accepted 25 June 2018)

\begin{abstract}
This study sought to explore the surfaces, textures and synthetic substance of discarded personal computer motherboards to produce mixed media paintings. The method employed in the study was experimental in its exploration of discarded pc motherboard as ground for mixed-media painting. All the paintings in the research were made using acrylic, oil colour, and motherboards on wooden board to achieve the rhythmic flow of colours, textures and forms. Safety wears such as nose mask and hand gloves were used to prevent injuries for the motherboards' sharp edges and the inhalation of dangerous particles. Using motherboard to do mixed media paintings enables the study to deviate from traditional conventions and create new possibilities that expand the visual, technical and aesthetic vocabulary in studio practice. This has opened up a trajectory for further experiment in "extraneous" materials as vehicles for visual expression.
\end{abstract}

\section{INTRODUCTION}

Since the advent of the art of painting, several approaches and media have been employed by painters. Prehistoric artists painted the representation of animals they hunted on their cave walls with pigments made by grinding earth and rocks mixed with animal fat (Useherwood 2008). From these early artistic works on rock surfaces, over the centuries, artists have used different painting grounds to express their creativity. Of these many grounds, the canvas has probably been the most enduring. Whatever the materials used in a work of art, definition and evaluation are subjective. Wollheim (2002) distinguishes between three approaches to assessing aesthetic value. First is the realist, whereby aesthetic quality is an absolute value independent of any human view; second is the objectivist, whereby it is also an absolute value, but dependent on general human experience; and third being the relativist position, whereby it is not an absolute value, but depends on, and varies with, the human experiences. However one tense to see art, its nuances are subjectivities that implicate the processes of production, materials employed, the art created, how it is displayed, and its interaction with the audiences. In that sense, Usherwood (2008) notes that one needs have eyes that see possibilities since, for someone with artistic temperament, the whole world is a canvas. He goes further to conclude that to limit art to only few chosen media would be doing it a grave injustice. This position highlights the creative freedom inherent in artistic production and consumption, which does in fact enable artists to not just select media, but also to mix them as the creative impetus directs.

For an artist, one of the advantages of today is that there are new media of expression, which have advantageous attributes because they are synthetic, rather than natural. According to Jensen (2005) new synthetic media are inexpensive, fast drying with a permanency unmatched by traditional media, unchanged in value and clout when dry or wet, and can adhere to a wider variety of surfaces than traditional media.

While developments in the art would have made new media and techniques of application available to artists, technological advancements have also changed the way life is lived. Today, there are cell phones, personal Computers (PCs), personal digital assistants (PDAs), etc. that help us in communicating, organizing, research, process, transmit and store various types of data. Since newer models of these gadgets are regularly being produced and older ones are ending their life circles, a good quantum of electronic wastes is generated in today's cities. In Nigeria, as with other transitional economies, the problem is even more compounded. Most people cannot afford new gadgets like personal computers. To fill the gaps, people are buying imported second hand PCs from Europe and America. These ones are far cheaper for most people to afford. However, most of these second hand personal Computers imports have virtually completed their life circles, meaning that most will not last in the hands of their new owners. As they get discarded, more

Okon Ayi, Department of Visual Arts and Technology, Cross River University of Technology, Calabar, Cross River State, Nigeria.

(C) 2018 Bachudo Science Co. Ltd. This work is licensed under Creative Commons Attribution 4.0 International license. 
electronic waste is generated, without the possibility for industrial recycling. In the final analysis, the environment gets to be degraded because of discarded electronic wastes, such as pc casings and motherboards.

However one apprehends artistic production (Wollheim 2002), the most fundamental factor is that our entire world is a canvas for creativity (Usherwood2008). And, that being the case, electronic wastes discarded in the Nigerian environment, for instance, are a synthetic part of our world. In that sense, they can become the canvas for the expression of art. Therefore, using a range of electronic motherboards as canvas, this study sought to explore the surfaces, textures and synthetic substance of discarded pc motherboards to produce mixed media paintings. Being that in Nigeria, there are no industries to recycle motherboards that degrade the environment; this study furthers a green consciousness by repurposing these electronic wastes and also contributing to the development of visual aesthetic practices.

\section{MATERIALS}

The materials used in this studio experimental study included discarded motherboards picked from dump sites, plywood, oil paints, carpenter glue and wire. Visual data for the research was collected from sketches, photographs and life studies of social activities within Calabar and Lagos cities.

\section{METHODOLOGY}

The method employed in the study was experimental in its exploration of discarded pc motherboard as ground for mixed-media painting. In terms of approach, scrap pc motherboards were gathered from various garbage dumps near electronic workshops in Calabar Municipal Council, Cross River State, Nigeria.

Wooden grounds were prepared by sanding and dusting. Then sketches were transferred to the ground using the free hand approach, which enables fluid maneuverability.

Various grey scale and colour sketches were made from nature and photographs taken of social life in Calabar and Lagos.

The motherboards were cut into different shapes and sizes, since parts of the components create surface texture. The motherboards were stuck and screwed on to a wooden board with either the rough or smooth surface facing up, to create the required texture. Splash, drag and splatter methods were used and the colours were spread and scumbled at random, and monitored to see what recognizable imageries evolved. Pallet knife and bright colours were used to create highlights.

\section{Theoretical Frame Work}

Lowenfeld and Britain (2009) assert that no art expression is possible without selfidentification with the experience expressed as well as with the material by which it is expressed. This is one of the basic factors of any creative expression: it is the true expression of the self. The art materials are controlled and manipulated by one individual, and the completed project is the artist's. The expressionism theory, popularized by Leo Tolstoy, is primarily concerned with the expression and communication of emotions. This theory is applicable in Jackson Pollock's Lucifer (Plate 1) (Gardner, 1980).

By dragging, dripping and splattering paint in a process of excited movement, the artist traces and retraces a remarkable coherence of direction and pattern. The painter strives for unplanned immediacy, directness and for an effect of unstudied spontaneous freshness of statement. This coincides with his theory, "I don't work from drawing or colour sketches. My painting is direct the method of painting in the natural growth out of a need. I want to express my feelings rather than illustrate them" (Chip, 2010). Pollock concludes in his philosophy that technique is just a means of arriving at a statement.

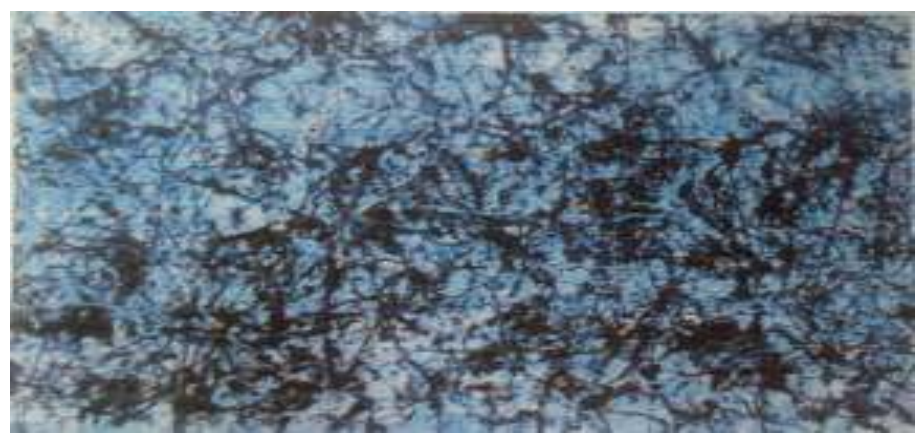

Plate 1: Jackson Pollock's Lucifer (1947)

Medium: Oil, aluminum paint and enamel on canvas 
According to Russell (2000), all the visual arts communicate some level of human expression that can be expressed through a wide range of media, materials and techniques. This point is exemplified in the works of contemporary artists, who discovered how to work with several traditional and new media, mixed in one work. In that sense, Noel (2002) submits that these new discoveries developed and deviated from the canons of imitation, which was based on the outward aspect of things. The artists employed new media and styles of expression in their artworks. In that sense, new art forms tend to arise from new needs and new possibilities. Therefore, this research is based on the expression theory of art because the motherboards and splattered paint enabled the researcher to experience and express emotional states that transcend the materiality of the paint and the electronic wastes.

\section{Literature}

Bruce Onbobrakpeya has made art that inspired several generations of African artists. From 1995-2005, his works were characterized by the arrangement of discarded computer motherboards (Plates 2). The unconventional materials that have been sourced by him and used in making art works, exemplify the height of material appropriation, born out of the need to solve societal and personal artistic problems. The Arizona based artist, Joe Dragt, used motherboards as an art medium and also used computer components as painting grounds (Plate 3). He conceive that the complex circuitry of motherboards would be great backgrounds for his paintings. He meticulously unscrews every component, sends parts he does not need to recycle companies, and uses the boards as aesthetic surfaces. On his part, Carlos Printe (Plate 4) used the computer motherboards as the background of the works he painted.

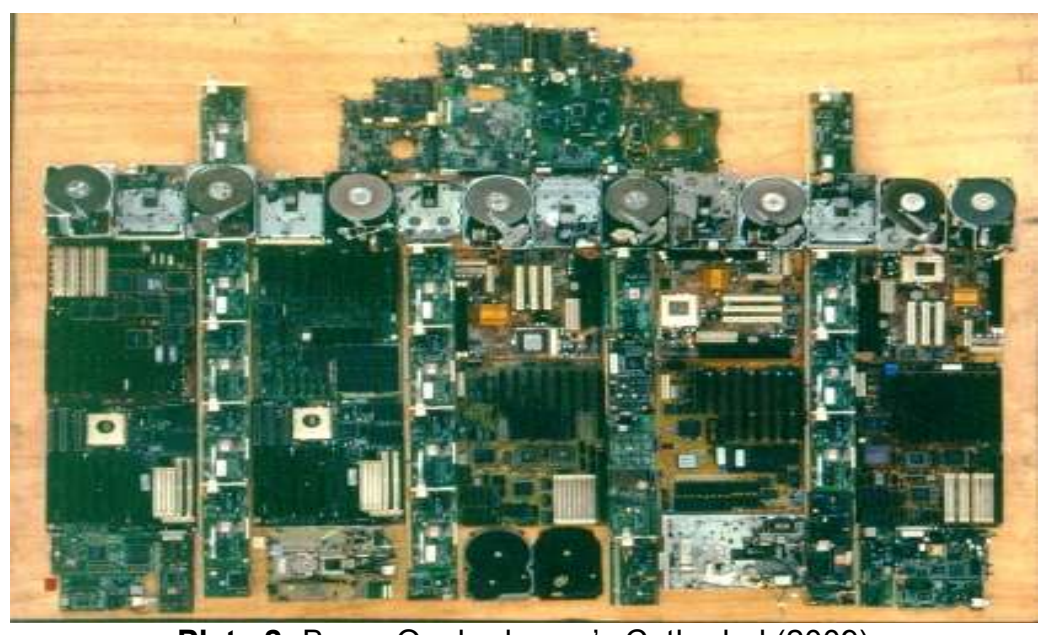

Plate 2: Bruce Onobrakpeya's Cathedral (2009)

Medium: Computer motherboards on wood

Size: $72 "$ x 106"

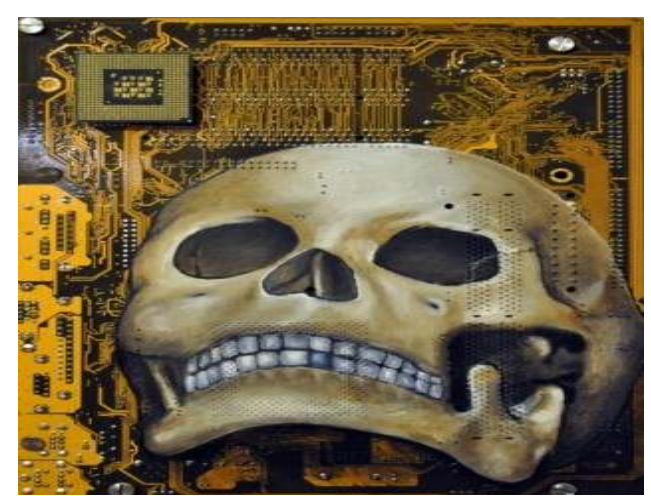

Plate 3: Joe Dragt's Blue tooth (2012)

Medium: Oil on motherboards

Size: $20 \times 24$ 


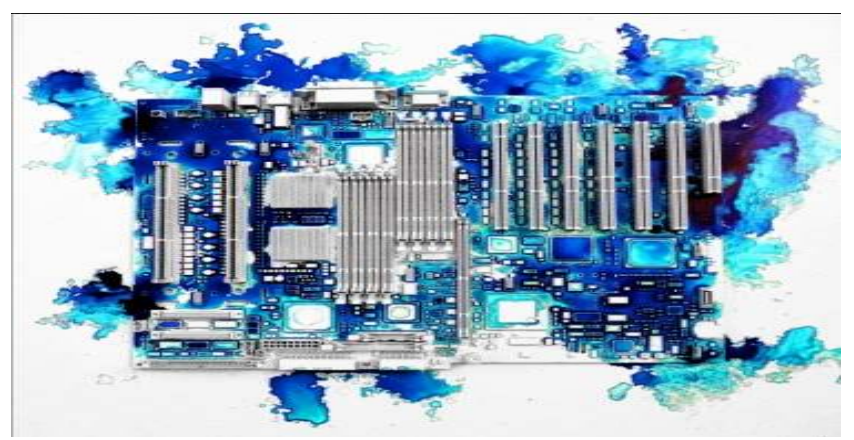

Plate 4: Carlos Printe's Soaked (2013)

Medium: Motherboard

Size: $20 \mathrm{~cm} \times 24 \mathrm{~cm}$

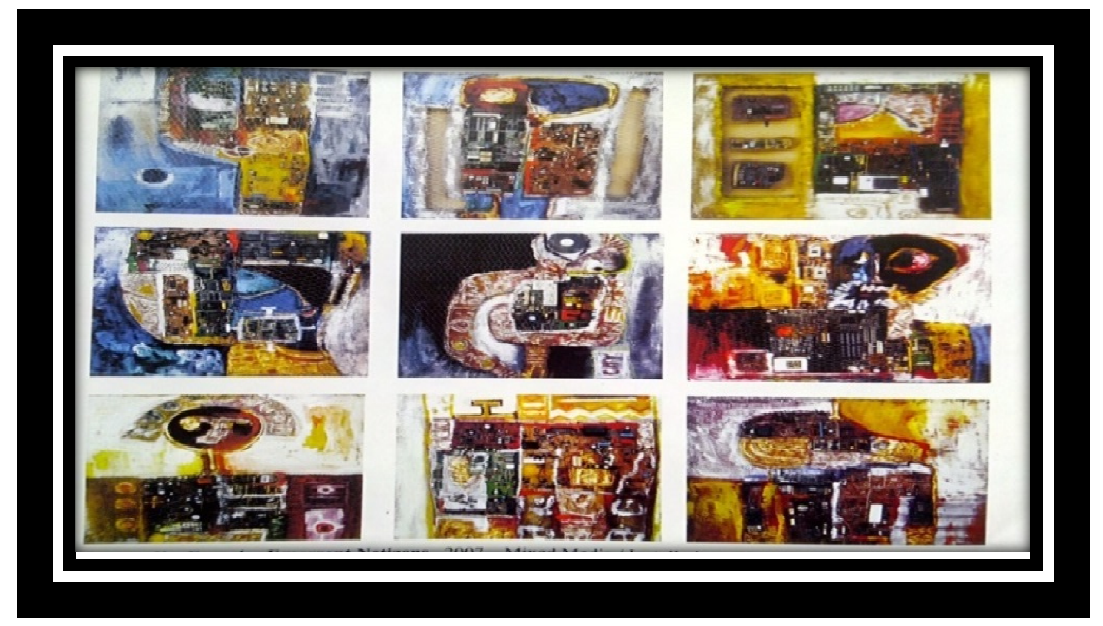

Plate 5: Ikechukwu Francis' Nitezens (2008)

Medium: motherboards on wood

Size: $60 "$ x 109"

The texture is done with gesso applied with a brush, partially covering the circuit board. A motherboard is a multifaceted PCB (printed circuit board) which is the fundamental element of a lot of electronic devices, predominantly personal computers, cellular devices, stop watches, clocks, etc. it consists of a lot of important elements of a personal computer like main memory, microprocessor, microprocessor's sustaining chipset that offers connection between the central processing unit and additional peripheral elements. A new media artist like Ike Francis ahs painted portraits and landscapes using found circuit boards and other electrical equipment. His works such as Netizens (Plate 5) combines found circuit board to form images that reference urban grids and portraiture simultaneously, as motherboard represent both anthropomorphic features and an aerial view of the urban architecture. Ike Francis encourages his students to use materials found in their everyday environment.

The most important achievement of new media such as the motherboard is the new freedom and vitality it has provided by expanding the visual and technical vocabulary for researchers and artists alike. In direct affirmation of this, Jensen (2005) contends that artist cannot be restricted to the possibilities of traditional media. The author opines that each painting medium, with its individual qualities of brush stroke, colour, and texture, produces an 
effect unique unto itself. Thus, as Russeu (2003) has suggested, a new painting medium is as important to the artist as is a new building material to an architect. Therefore, even if the "new" medium drafted by the artist seems extraneous to art, the artist still has the creative freedom to establish it as artistic material. The word extraneous refers "to something not directly connected with the situation you are in or the subject you are dealing with" (Hornby 2006). According to Lingvo (2009), the word refers to whatever is not an inherent part of the given consideration or entry. It stresses something that is not or has no bearing but is otherwise very general in its implication, having no bearing on, or connection with the subject at issue. However, in the context in which the artist has the creative prerogative to determine the non-traditional media to employ, even if that medium seems extraneous (Hornby 2006, Lingvo 2009), it s still very important to the artist (Russeu 2003, Jensen 2005).

Along with the importance of a new medium of painting, such as motherboards, what is also important is the colour medium that is applicable in the media mix. Since the motherboard is synthetic, the researcher chose oil paint as the colour medium, because of its good binding abilities. Oil paintings are created by suspending pigments in oil or oil-based medium, such as a mixture of oil, varnish, and turpentine (Moore 2009). According to Jensen (2005), Herbert Van Eyck (1370-1426) is popularly credited with the invention of oil painting. Lucia (2008) is of the opinion that many artists, including Leonardo da Vicni, experimented with the addition of oils to tempera in an effort to expand the technical range and the expressive potentialities of the traditional egg tempera medium. One of Leonardo's most famous experiments, the Last Supper, developed major irreparable defects during his lifetime. This would not have been so, if he had used oil paint. Mayer (in Moore 2009) points out that whereas other paint media are employed for certain advantages they have over oil, the later remains standard because the majority of painters consider that its advantages outweigh its defects. In scope and flexibility, it surpasses media such as watercolour, tempera, fresco and pastel. From a technical point of view, Jensen (2005) opines that all traditional explain that encaustic painting combines pigment with wax, fresco combines pigment in explain that encaustic painting combines pigment with wax, fresco combines pigment in aqueous solution with plaster, egg tempera combines pigment with egg yolk, pastel combines dig pigment with a weak solution of gum Arabic, water colour combines pigment with an (2009), the primary advantage of oil paint is that is offers the greatest flexibility, easy manipulation, adapting to a wide range of effects and is universally accepted by the artists and public, compared to traditional media.

Ever since the era of cave paintings, painting has evolved through exploration and experimentation to meet artists' needs. Jensen (2005) affirms that, new art forms arise from new needs and new possibilities. The much diversity of technique, style and media evolve as artists clamour to carve a niche for their personal identity in the field of painting. Jensen (2005) further agrees that painting media have exerted a profound influence on the character of the forms that have emerged from each succeeding era. In this era, motherboards are parts of the wastes generated from our technological world, which an artist can appropriate for painting.

\section{DISCUSSION}

This study explored different dimensions and approaches to using the motherboard as painting medium. During the studio experiments, several studies were made in experiments that culminated in a number paintings (Plates 6 to 13). 


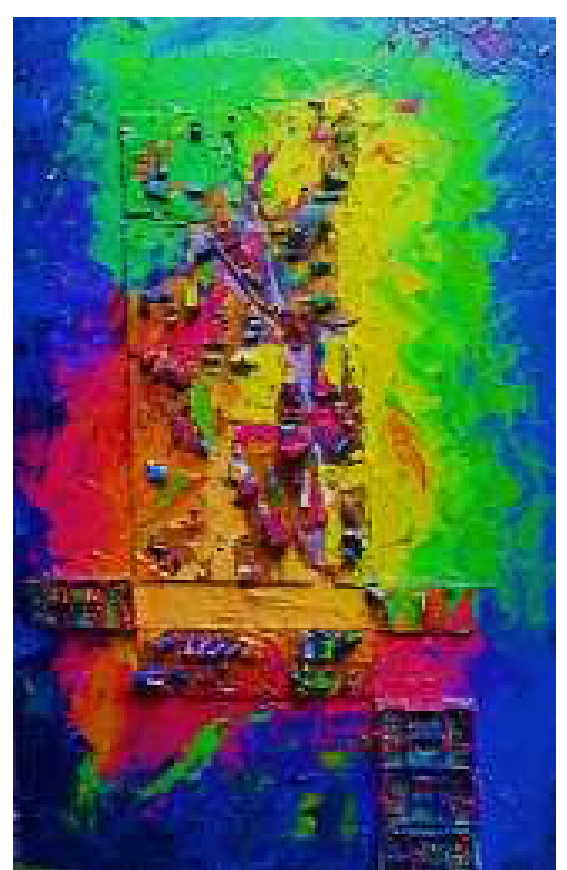

Plate 6: Obong of Calabar (2013)

Medium: Oil, motherboards on wood Size: $16 "$ x $24 "$

Plate 6 is an interpretation of the Obong of Calabar's palace, with him at a meeting with the elders and his people. The motherboard, with its cacophony of electronics, represents the people and the colours indicate growth, royalty, wealth and peace.

In Plate 7, Sagacity, made with oil paint, wire and motherboards on wooden board, represents Calabar. The city is popularly called the "Canaan City" in collusion to the Biblical "promised" and flourishing land of Canaan, which was said to "flow" with milk and honey. In contrast to the insecurity in many parts of Nigeria, Calabar is a small, peaceful and secure city where people go about their daily

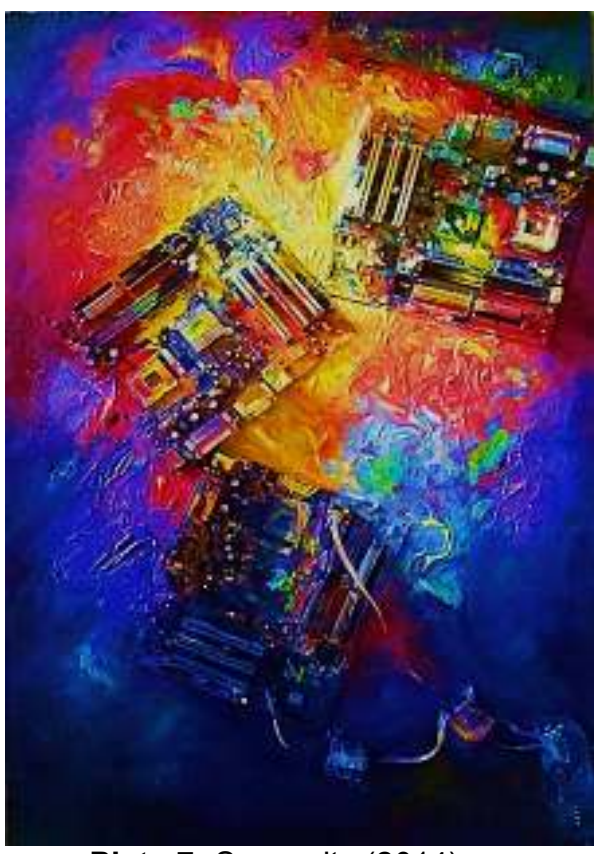

Plate 7: Sagaccity (2014)

Medium: Oil, motherboards on wood Size: $24 "$ x 36 "

businesses without fear of Boko Haram Islamic terrorists or the myriad militants agitating in the Niger Delta region. The motherboard represents the technology of communication, which eases business and social interactions, mobility, and the actualization of security in Calabar. The configuration of the three motherboards represents populations in the old city, its new settlements, as well as the interior towns adjoining. The bright colours represent a developing city vibrant in culture production and consumption. For, it is in Calabar that the annual Carnival Calabar takes place. In this painting, the blue shows calmness, peace and joy

in

the

city. 


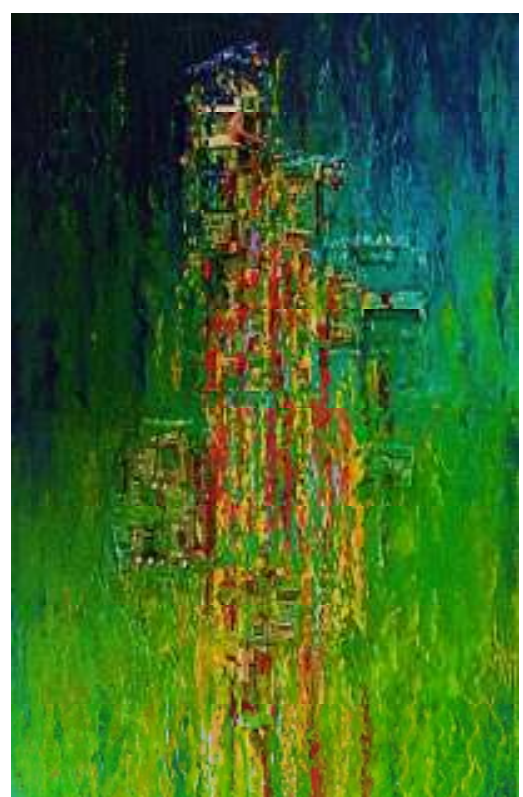

Plate 8: Expectation (2013)

Medium: oil, motherboards on fabric Size: $20 "$ x 36 "

Expectation (Plate 8) is a textured interpretation of human wants and needs, interspersed by the greenness of envy and greed. The painting has a dramatic flow of dripping colours that cover the motherboards. The motherboards represent the people, while the dripping colours are their expectations from the state, its apparatuses, and the society at large. Within these expectations, contestations are inevitable, just as are envy and greed, which drive negative activities in human societies.

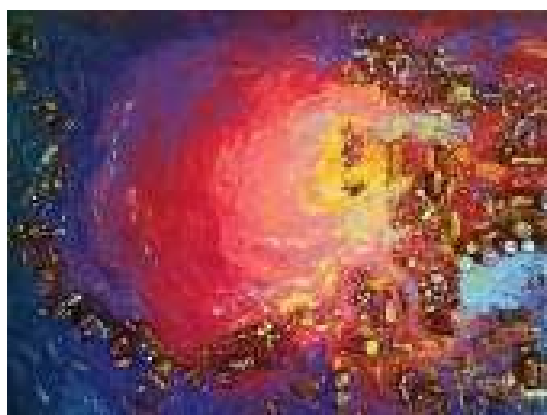

Plate 10: Summer (2013)

Medium: oil, motherboards on wood Size: $20 "$ x 24"

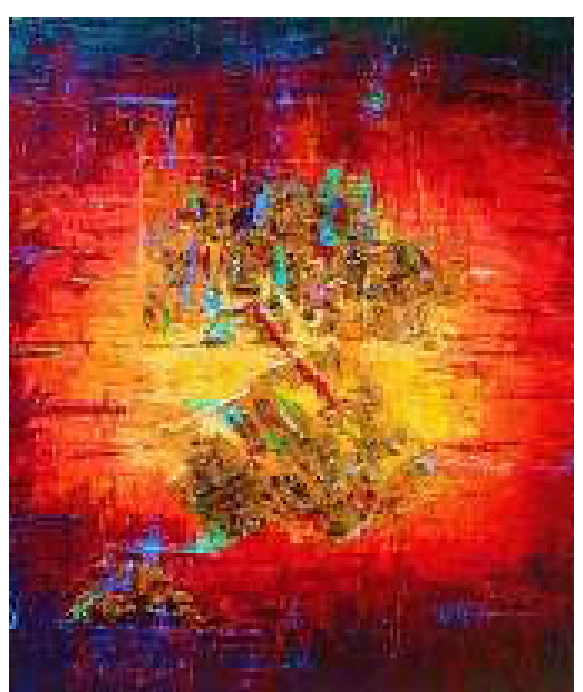

Plate 9: Akpap-Okoyong Market (2013) Medium: oil, acrylic, motherboards on fabric Size: $24 "$ x 36 "

Plate 9 is Akpap-Okoyong Market, made in oil, acrylic paint and motherboards on fabric. It is a major market in Odukpani local government area of Cross River State. In this painting, the colour flows with quiet iridescence across the surface of the motherboards and portrays people and products from different places. Here, the researcher uses the bright red and yellow radiating out of deeper backgrounds speckled with touches of blue, to show the economic importance of goods and services in the populated market.

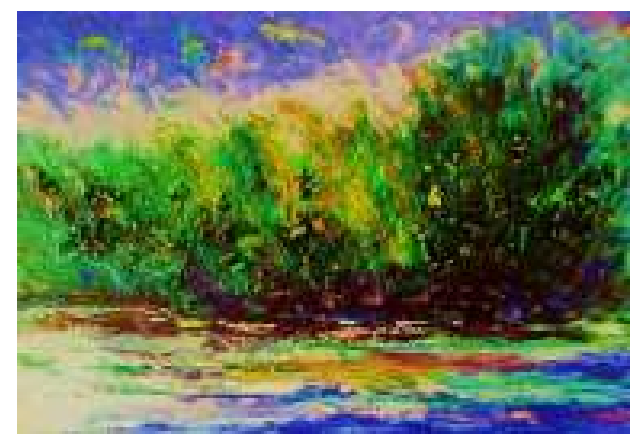

Plate 11: Echo of Communication (2013)

Medium: watercolour, oil, motherboards on fabric Size: 24 " x 36 " 
Made in oil, motherboards on wooden board, Summer (Plate 10) is a creative rendition of a seascape in an aerial view, showing parts of the busy beach on the left side. The painting if flooded with sensuous light and colour, which unite the sea, the multitudes on the beachside, and he architecture-represented by the electronic textures of the motherboard.

In Echo of Communication (Plate 11), the dramatic flow of colour depicts the turbulent effect of wind on trees by the riversides, as occasionally experienced in many areas of Calabar. The vibrant surface is achieved through a careful manipulation of motherboards, and oil colours painted with palette knife. The choice of colours is rendered in rich blue and green, with a sparkle of brown, purple, orange etc., which unify the painterly elements.

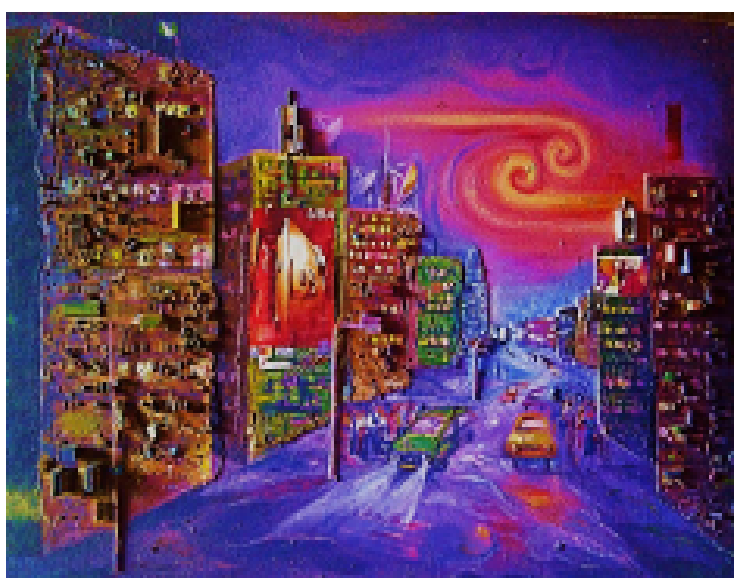

Plate 13: Sunday, Eko at 6:30pm (2012)

Medium: Oil paint, motherboards on wood Size: $24 "$ x 48"

circuitry indicates, all tenants in all floors of the skyscraper are inextricably linked in one common existence.

\section{CONCLUSION}

it scorches the earth. In this visual imagery, the electronic sky-scraper (motherboard) reaches out to the dynamics between the earth, the ozone layer and global warming.

In Sunday, Eko at 6:30pm (Plate 13), the motherboards, again, represent the architectural aspirations of a growing city. "Eko" is the Yoruba name for Lagos, the ever busy economic capital of Nigeria. In this painting, it is 6:30pm on Sunday evening in Lagos. The usual crowds are absent on this day. While cars speed past on the street below, the skyscrapers reach out to the heavens, drawing attention to the rhythmic designs etched by the light in the clouds above. The circuitry of the motherboards represent both the floors of the skyscrapers themselves, and the gadgetry that each floor holds in service to its tenants. In the end, as the

\section{All the paintings in Plates 6-13 were} made using acrylic, oil colour, and motherboards on wooden boards to achieve the rhythmic flow of colours, textures and forms. During the work process, the danger of the motherboard's sharp edges was overcome with the use of a drilling machine, hand gloves and a nose mask to prevent the inhalation of dangerous particles. The motherboard is water resistant, strong and easily manipulated with oil paint, to play-up the mixing of new and older media in concert with a mixed painting technique. This study's deviation from the conventional usage of pigments and other traditional painting media has created new possibilities that expand the visual, technical 
and aesthetic vocabulary in studio practice. The paintings made in this study defy traditional conventions. As Pollock stated (Chipp, 2010), "the method of painting is the natural growth out of a need". At the core of this philosophy of doing away with the reliance on traditional media and materials, the researcher's quest for freedom of exploration, expression and imagination was successfully achieved by doing mixed media paintings with motherboards, thereby creating a pedestal for further experiment in "extraneous" materials as vehicles for visual expression.

\section{REFERENCES}

Bartolome, E. B., 2008. Art and Artists. California: University of California Press.

Birren, F., 2009. History of Colour in Painting. New York: Van Nostrand Reinhold.

Blake, W., 2009. Creative Colourfor the Oil Painter. New York: Waston-Guptill Press.

Carson, L., 2006. Media Awareness: www.Answer.Yahoo.Com/question/inde $\mathrm{x} l$.

Retrieved on March 18, 2010. 